\title{
A rare cause of acute malnutrition: Non-germinoma
}

\author{
(D) Deniz Honamlı', (1) Melike Arslan², (1) Necati Balamtekin² \\ 1 University of Health Sciences Turkey, Gülhane Faculty of Medicine, Department of Pediatrics, Ankara, Turkey \\ 2University of Health Sciences Turkey, Gülhane Faculty of Medicine, Department of Paediatric Gastroenterology, Ankara, Turkey
}

\section{Date submitted:}

03.03.2020

Date accepted:

08.06.2020

Online publication date:

15.03.2021

\section{Corresponding Author:}

Melike Arslan MD, University of Health Sciences Turkey, Gülhane Faculty of Medicine, Department of Paediatric Gastroenterology, Ankara, Turkey melikearslan190@gmail.com

ORCID:

orcid.org/0000-0002-0107-4699

Keywords: Malnutrition, nongerminoma, child

\begin{abstract}
Energy needs of children are high, hence, malnutrition adversely affects body functions of children. Supportive therapy must be starter early in order to prevent weight loss, morbidity and mortality. Malignancies are frequent among the etiology of malnutrition. Considering the coexistence of malnutrition and childhood cancers, early diagnosis is essential. In this study, we aimed to present an adolescent patient with acute malnutrition diagnosed as non-germinoma.
\end{abstract}

\section{Introduction}

Malnutrition is excessive deficiency of energy, protein or other nutrients. Energy needs of children are higher than adults and energy reserves are also limited. Disequilibrium of nutrients cause adverse effects on tissue, body function and clinical outcome (1). Malnutrition causes mortality and morbidity in children because of the increased risk of infection, disrupted immune system, delayed in wound healing, and dysfunctioning in gastrointestinal barrier (1). According to the functional categorization of weight loss, the reasons were divided into three categories as excess calorie need (diabetes mellitus, chronic chest and heart disease, hyperthyroidism, inflammatory diseases), insufficient calorie intake (malignancies, psychiatric disorders), and absorption disorders (diabetes mellitus, celiac disease, lactose intolerance, pancreatic insufficiency, gastroesophageal reflux) (2). We here report an adolescent patient hospitalized for acute malnutrition and diagnosed with non-germinoma.

\section{Case Presentation}

A previously healthy 17-year-old boy was admitted to the Department of Pediatric Gastroenterology with a 4-month history of nausea which was more severe in the morning and was not associated with eating, decreasing loss of appetite and significant weight loss. He reported weight loss from 58 to 41.5 $\mathrm{kg}$ in in the last four months. His complaints had begun with flu-like symptoms, fever, stomachache, nausea, vomiting, and myalgia. He reported to have lost around seven kilogram (10\%) during the first week of the symptom initiation. His physician prescribed intramuscular antibiotics for five days. He reported symptom relief following this treatment. However, a complete recovery was not present and the patient continued to lose weight to $41.5 \mathrm{~kg}$, reaching $28 \%$ during these four months. On admission, he was conscious, and his temperature was 36.7 ${ }^{\circ} \mathrm{C}$; heart and respiratory rates and systolic and diastolic blood pressure values were normal. He was $41.5 \mathrm{~kg}(p<3), 170 \mathrm{~cm}$ $(\mathrm{p} 10-25)$ and his body surface area was $1.32 \mathrm{~m}^{2}$. According 
to physical examination, he was pallor, cachectic. Other examinations were normal. In addition, he was consulted to the Department of Child Mental Health and Disease, anxiety and depression were detected secondarily. On the other hand, he was examined for substance abuse because his father convicted of substance trafficking and he was neglected by the family. For the purpose of excluding substance abuse, he was observed during hospitalization. In the process of diagnosis, ondansetron ( $0.15 \mathrm{mg} / \mathrm{kg} / \mathrm{dose}$ ) was given to cease nausea. Total parenteral nutrition therapy was given for the purpose of preventing weight loss. Oral nutrition was continued to ensure that the total daily energy intake was $3000 \mathrm{kcal} / \mathrm{day}$ and enteral feeding solution was also started. Endoscopy was performed for diagnosis. Proton pump inhibitor was given to him because gastritis was shown via gastric biopsy. However, the cause of this sudden severe weight loss could not be explained. Thyroid-stimulating hormone (TSH) and free T4 were $2.49 \mathrm{mlU} / \mathrm{mL}$ and $0.59 \mathrm{ng} /$ $\mathrm{dL}$, respectively. Secondary hypothyroidism was diagnosed because TSH did not respond to free T4 level. Then, follicle stimulating hormone, luteinizing hormone, prolactin, cortisol (morning serum), and insulin-like growth factor-1 were $0.2 \mathrm{mIU} /$ $\mathrm{mL},<0.2 \mathrm{mlU} / \mathrm{mL}, 223 \mathrm{ng} / \mathrm{mL}, 1.48 \mathrm{mcg} / \mathrm{dL}$, and $32.28 \mathrm{ng} / \mathrm{mL}$, respectively. These results and $\mathrm{ACTH}$ stimulation test showed that his diagnosis was panhypopituitarism. Hence, the mass between suprasellar cistern, optic chiasm and prepontine cistern was detected via pituitary magnetic resonance imaging (MRI). A stereotactic biopsy was taken from the supercellular cistern and nongerminoma was diagnosed. Serum alpha-fetoprotein (AFP) and beta-hCG were $2.85 \mathrm{ng} / \mathrm{mL}$ and $1.55 \mathrm{IU} / \mathrm{L}$, respectively. Because of normal level of AFP and beta-hCG and no two or more foci on cranial MRI, no positive sign on spinal MRI and negative cerebrospinal fluid-cytology, it was considered as nonmetastatic standard risk non-germinoma. Hence, three cures of PEI (cisplatin, etoposide, ifosfamide) were given. A cure of PEI was given after reevaluation. Finally, treatment was achieved successfully via 54 gy (TrueBeam) radiotherapy. His weight was recorded $60 \mathrm{~kg}$ after the treatment. He is still being followed up in child gastroenterology, endocrinology and oncology monthly. He was informed about his disease and procedure, and the informed consent was received from the patient.

\section{Discussion}

The patient had nausea and vomiting. Nausea is a subjective term which can be defined as a feeling in the predictive symptom of vomiting. Vomiting occurs by repetitive forceful contraction of abdominal muscles which cause higher pressure in abdominal part and gastric content discharge into the mouth. Many reasons which may be physiologic responses to underlying disease related to gastrointestinal tract, central nervous system or other system may cause nausea and vomiting (3). Causes of nausea and vomiting include medication, infections, gastroesophageal reflux, bile reflux gastritis, eosinophilic gastroenteritis, helicobacter disease, pancreatitis, anatomic abnormalities, central nervous systems diseases (migraine, increased intracranial pressure, congenital malformation, seizure disorders), psychiatric disease (psychogenic vomiting, anxiety disorders, depression, anorexia nervosa, bulimia nervosa), and endocrinologic and metabolic causes (4).

Malnutrition in any disease, including cancer, is the result of combination of decreased intake, increased loss (including malabsorption) and risen needs (5). A significant factor that contributes to malnutrition in pediatric oncology patients is inflammation because cytokines released by the tumor may alter protein, lipid and carbohydrate metabolism and cause weight loss (6). Changes in metabolism of carbohydrate, fat and protein have been shown in oncologic patients (5). Moreover, increased lipid breakdown between these changes leads to the depletion of lipid stores and changes in carbohydrate metabolism, and all these changes cause energy loss. In addition, there is an increased protein cycle and loss of normal compensation mechanisms seen in hunger. The final result is malnutrition, which is especially associated with loss of lean body mass (5).

It is suggested that nutritional state is vulnerable to infections by causing hormonal changes and poor cytokine response in childhood cancer patients. Secondly, it is argued that nutritional status may be an effective factor on mortality in malignancy patients (7). While initiating therapy, malnutrition may decrease the effectiveness of anticancer therapy by decreasing the absorption of chemotherapeutic drugs and poorly tolerated dose density (7).

Both the malnutrition at the diagnosis of malignancy and the malnutrition in the third month after diagnosis were associated with a decrease in the survival rates. Unlike malnutrition detected in diagnosis, insufficient feeding in the third month may be prevented by strict monitoring of the nutritional status and, if necessary, rapid intervention (7). Our patient had acute malnutrition $(41.5 \mathrm{~kg}, \mathrm{p}<3)$ at the time of diagnosis and reached the ideal body weight $(60 \mathrm{~kg}, 10-25 \mathrm{p})$ at the end of treatment with strict follow-up of the nutritional status of him during the disease process.

\section{Conclusion}

Malnutrition causes severe morbidity and mortality in children because of increased risk of infection, disruption in immune system, delay in wound healing, and dysfunction in gastrointestinal barrier. One of the reasons of energy deficiency is malnutrition because of that energy intake is insufficient to meet energy need. In childhood cancer patients, a significant factor on insufficient feeding is inflammation, and malnutrition is frequent at diagnosis time in this population. Consideration of coexistence of malnutrition and childhood cancers is important for early diagnosis and reduction of morbidity and mortality. 


\section{Ethics}

Informed Consent: He was informed about his disease and procedure, and the informed consent was received from the patient.

Peer-review: Externally and internally peer-reviewed.

\section{Authorship Contributions}

Surgical and Medical Practices: D.H., M.A., Concept: D.H., M.A., Design: N.B., Data Collection or Processing: D.H., M.A., Analysis or Interpretation: D.H., N.B., Literature Search: D.H., M.A., Writing: D.H., M.A., N.B.

Conflict of Interest: No conflict of interest was declared by the authors.

Financial Disclosure: The authors declared that this study received no financial support.

\section{References}

1. Joosten KF, Hulst JM. Prevalence of malnutrition in pediatric hospital patients. Curr Opin Pediatr. 2008;20:590596.

2. Maqbool A, Liacouras CA. Major symptoms and signs of digestive tract disorders. In: Wilson Nelson Textbook of Pediatrics 21st Ed. Philadelphia: Elsevier. 2020;19021907.
3. Quigley EM, Hasler WL, Parkman HP. AGA technical review on nausea and vomiting. Gastroenterology. 2001;120:263286.

4. Quigley EMM. Motility and dyspepsia. In: Johnson DA, Katz PE, Castell DO, eds. Dyspepsia. Philadelphia: ACP. 2000:79-96.

5. Alessandra S, Pencharz P, Barr RD. children, cancer, and nutrition--a dynamic trianglein review. Cancer. 2004;100:677-687.

6. Brinksma A, Huizinga G, Sulkers E, Kamps W, Roodbol $P$, Tissing W. Malnutrition in childhood cancer patients: a review on its prevalence and possible causes. Crit Rev Oncol Hematol. 2012;83:249-275.

7. Loeffen EA, Brinksma A, Miedema KG, de Bock GH, Tissing WJ. Clinical implications of malnutrition in childhood cancer patients--infections and mortality. Support Care Cancer. 2015;23:143-150. 